\title{
Effect on survival after myocardial infarction of long-term treatment with phenytoin
}

\author{
THOMAS PETER ${ }^{1}$, DAVID ROSS, ANNE DUFFIELD, MICHAEL LUXTON, \\ RICHARD HARPER, DAVID HUNT, AND GRAEME SLOMAN
}

From the Department of Cardiology, Royal Melbourne Hospital, Melbourne, Australia

SUMMARY A prospective, randomised, open trial was performed in 150 patients to test for any beneficial effects on 2-year mortality of long-term antiarrhythmic therapy with phenytoin in patients with acute myocardial infarction. Patients were stratified according to age, sex, past history of myocardial infarction, and the presence or absence of electrical or mechanical complications in the course of acute infarction. They were then randomised to treatment or control groups (74 v. 76). The former received phenytoin in doses aimed at maintaining plasma phenytoin levels between 40 and $80 \mu \mathrm{mol} / \mathrm{litre}$. All patients entered the study before discharge from the coronary care ward. Plasma phenytoin levels were in the therapeutic range in between 51 and 75 per cent of subjects at any one follow up visit. There were 19 withdrawals from the treatment group, 10 of which were the result of side effects. There were 5 withdrawals from the control group. According to the original intention to treat, there were 18 deaths at 2 years in the treatment group and 14 deaths in the control group. There was no reduction in the incidence of instantaneous or sudden deaths. Deaths on treatment were not associated with a low phenytoin plasma level. Phenytoin treatment showed no beneficial effects on mortality and was associated with a high incidence of side effects.

Several trials of the effects of long-term antiarrhythmic therapy in survivors of acute myocardial infarction have been reported (Amsterdam et al., 1968; Collaborative Group, 1971; Reynolds and Whitlock, 1972; Kosowsky et al., 1973; Ahlmark et al., 1974; Wilhelmsson et al., 1974; Multicentre International Study, 1975). One collaborative group used phenytoin as an antiarrhythmic agent and made a post hoc observation that patients who had plasma levels of phenytoin above $10 \mu \mathrm{g} / \mathrm{ml}$ (equivalent to $40 \mu \mathrm{mol} / \mathrm{l}$ ) had a lower mortality in the first year after myocardial infarction than patients with blood levels below this level (Collaborative Group, 1971). This observation prompted this prospective study to determine whether long-term therapy with phenytoin, given in doses to maintain blood levels above $40 \mu \mathrm{mol} / \mathrm{l}$, would reduce the mortality of patients who suffered acute myocardial infarction.

\footnotetext{
'Present address: Department of Cardiology, Cedars-Sinai Medical Center, Box 48750, Los Angeles, California, 90048, USA.
}

Received for publication 13 February 1978

\section{Subjects and methods}

Between December 1972 and April 1974505 consecutive patients were admitted to CCU, of whom 220 were diagnosed as having a definite myocardial infarction (World Health Organization, 1971). Seventy of these patients were excluded from the trial because of one or more of the following: age 70 years or more, chronic diseases involving other systems, mental illness, language difficulties, chronic alcoholism, or additional unrelated heart disease. One hundred and fifty patients were, therefore, recruited to the study. Before randomisation, patients were grouped according to the presence or absence of mechanical and/or electrical complications identified in the CCU (Wilhelmsson et al., 1974):

Group I Neither electrical nor mechanical complications.

Group II Mechanical complications only.

Group III Electrical complications only.

Group IV Both electrical and mechanical complications. 
Electrical complications were defined as the presence of one or more of the following:

(1) Any ventricular arrhythmia except ventricular ectopic beats occurring with a frequency of less than 1 per 10 normal beats.

(2) Any atrial or junctional arrhythmia except occasional atrial and junctional ectopic beats.

(3) Any degree of atrioventricular block.

(4) Complete left or right bundle-branch block. Mechanical complications were defined as the presence of one or more of the following:

(1) Definite crepitations in the lungs which persisted after coughing in the absence of chronic pulmonary disease.

(2) Cardiogenic shock-defined as systolic blood pressure less than $90 \mathrm{mmHg}$ with oliguria, peripheral hypoperfusion, and obtunded conscious state.

(3) Radiological evidence of pulmonary venous congestion in at least one of the daily posteroanterior chest radiographs.

Patients in these groups were then stratified according to sex, age in years (less than 40,40 to 55, and 56 to 70), and the presence or absence of a past history of myocardial infarction. After stratification, patients were randomised to control (not receiving phenytoin), or treatment (receiving phenytoin) groups before discharge from the CCU.

The trial was conducted in an open manner: placebo was not given to the control group. Treatment was started before discharge from the CCU. Patients randomised to the treatment group received phenytoin (Dilantin-Parke Davis) in a dosage schedule of $1 \mathrm{~g}$ orally over 20 minutes on the first day, $500 \mathrm{mg}$ as a single dose on the second day, and $400 \mathrm{mg}$ on the third day, and thereafter according to the plasma level. Patients received phenytoin as a single dose during their stay in hospital and as divided doses twice daily after discharge from hospital.

All patients in the study were seen in a special coronary follow-up clinic at $1,2,4,6,9,12,18$, and 24 months after recruitment to the study. All patients, irrespective of their randomisation, were treated conventionally during the follow-up period. Thus beta-receptor antagonists and/or antiarrhythmic drugs were used if indicated. At each scheduled visit to the hospital the plasma level of phenytoin 3 hours after the last oral dose was estimated by a spectrophotometric method which is specific for phenytoin (Wallace, 1968); the dosage was adjusted if necessary to maintain the plasma level in the therapeutic range of between 40 and $80 \mu \mathrm{mol} / 1$ (Bigger et al., 1968).

Patients who were electively withdrawn from the study were also followed in the same manner.
In the event of death, all efforts were made, including review of official records and interviews with family and observers, to obtain a detailed picture of the circumstances of death. Deaths were classified into one of the following groups:

(1) Instantaneous: all deaths which occurred within 3 minutes after the onset of a new major symptom.

(2) Sudden, not instantaneous: all deaths which occurred within 24 hours of the onset of a new major symptom, but not within 3 minutes.

(3) Not sudden: all deaths which occurred 24 hours or later after the onset of a new major symptom.

The results were analysed using $\chi^{2}$ contingency tables. A P value of less than 0.05 was considered to be significant.

\section{Results}

The matching of treatment and control groups is shown in Table 1. The two groups were well matched according to the factors used for stratification. They were also well matched with respect to cigarette smoking and the time of recruitment to the study from the onset of acute myocardial infarction. They were not well matched according to the electrocardiographic localisation of infarction. There was a preponderance of anterior infarcts in the control group and an excess of inferior infarcts in the treatment group.

Table 1 Patient matching at entry

\begin{tabular}{|c|c|c|}
\hline & $\begin{array}{l}\text { Treatment } \\
\text { group }\end{array}$ & $\begin{array}{l}\text { Control } \\
\text { group }\end{array}$ \\
\hline $\begin{array}{l}\text { Total number } \\
\text { Sex }\end{array}$ & 74 & 76 \\
\hline Male & 62 & 60 \\
\hline Female & 12 & 16 \\
\hline \multicolumn{3}{|l|}{ Age } \\
\hline$<40$ & 5 & 3 \\
\hline $40-54$ & 35 & 33 \\
\hline $55-70$ & 34 & 40 \\
\hline Past history of myocardial infarction & 19 & 20 \\
\hline Cigarette smoking $>10$ per day & 30 & 32 \\
\hline \multicolumn{3}{|l|}{$\begin{array}{l}\text { Time of recruitment since onset } \\
\text { of infarction }\end{array}$} \\
\hline$<2$ days & 15 & 19 \\
\hline 2-4 days & 49 & 46 \\
\hline$>4$ days & 10 & 11 \\
\hline \multicolumn{3}{|l|}{$\begin{array}{c}\text { Infarct localisation on } \\
\text { electrocardiogram }\end{array}$} \\
\hline Anterior & 24 & 35 \\
\hline Inferior & 40 & 27 \\
\hline Other & 9 & 13 \\
\hline No electrocardiographic changes & 1 & 1 \\
\hline \multicolumn{3}{|l|}{ Complications during acute infarction } \\
\hline Group I (nil) & 10 & 7 \\
\hline Group II (mechanical only) & 21 & 21 \\
\hline Group III (electrical only) & 12 & 13 \\
\hline Group IV (mechanical and & & \\
\hline electrical) & 31 & 3.5 \\
\hline
\end{tabular}


Table 2 Concurrent drug therapy

\begin{tabular}{|c|c|c|c|c|}
\hline & \multicolumn{2}{|l|}{ Week four } & \multicolumn{2}{|l|}{ Two years } \\
\hline & Treatment & Control & Treatment & Control \\
\hline Antiarrhythmics & 7 & 5 & 2 & 1 \\
\hline \multicolumn{5}{|l|}{ Lipid lowering } \\
\hline drugs & 0 & 0 & 6 & 2 \\
\hline Digoxin & 10 & 19 & 12 & 22 \\
\hline Diuretics & 30 & 35 & 25 & 32 \\
\hline Antihypertensive & 4 & 5 & 7 & 6 \\
\hline \multicolumn{5}{|l|}{ Beta-receptor } \\
\hline antagonists & 5 & 3 & 13 & 11 \\
\hline Anticoagulants & 32 & 36 & 2 & 5 \\
\hline Tranquillisers & 4 & 9 & 5 & 9 \\
\hline Antidepressants & 0 & 2 & 2 & 9 \\
\hline
\end{tabular}

The usage of concurrent medication during the study recorded at 4 weeks and 2 years after recruitment to the study is shown in Table 2 . There was no statistically significant difference in the incidence of various drugs in the treatment group compared with the control group, but there was a trend to more digoxin usage in the control group. This was associated with a higher (but not statistically significant) incidence of clinical heart failure in the control group compared with the treatment group. If indicated by the clinical situation, beta-receptor antagonists were started during the study. At 2 years, 13 of the treatment group and 11 of the control group were receiving beta-receptor antagonists. These drugs were generally begun for treatment of angina or hypertension. Concurrent antiarrhythmic drugs were discontinued whenever possible and only small numbers of patients in either group were receiving such therapy at the end of the trial.

During the follow-up period there were 24 withdrawals from the study, 19 from the treatment group and 5 from the control group. This was a withdrawal rate of 26 per cent from the treatment group and 7 per cent from the control group. Twelve of the withdrawals from the treatment group were elective and were generally the result of the development of a skin rash (8 of 12 cases). The rashes were not associated with toxic phenytoin levels and were caused by idiosyncrasy. One patient developed a severe form of the Stevens Johnson syndrome. Two patients could not tolerate long-term phenytoin therapy for reasons other than skin rash, one because of persistent vertigo and the other because of persistent nausea. One further patient developed carcinoma of the lung necessitating withdrawal from the study, while another moved to a distant city. Only one withdrawal from the control group was elective and was caused by the patient moving out of the study area.

Phenytoin plasma levels in the treatment group are shown in Fig. 1. Though the mean levels at

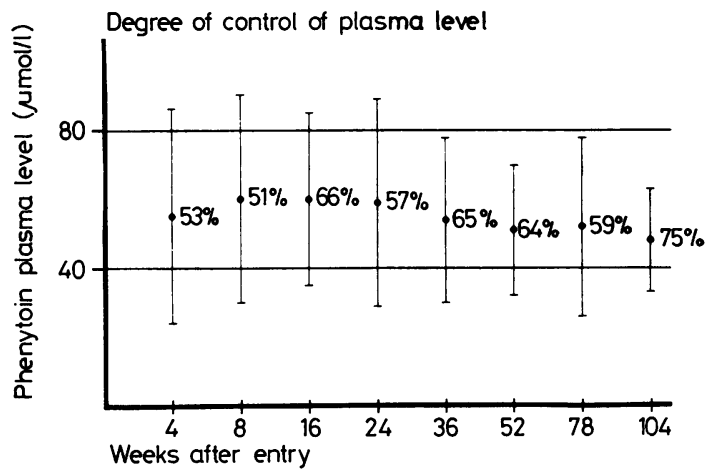

Fig. 1 Degree of control of plasma level. Dots (.) represent mean phenytoin plasma levels at each follow-up visit. One standard deviation either side of the mean is represented by bars. The percentage of patients at each visit with plasma levels in the therapeutic range is shown.

each visit were within the therapeutic range, there was a wide scatter such that the percentage of patients with plasma levels in the therapeutic range at any visit lay between 51 and 75 per cent.

The incidence of toxic phenytoin plasma levels at each scheduled visit and the incidence of symptoms attributable to phenytoin toxicity is shown in Table 3. Ataxia, diplopia, light headedness, dizziness and nausea were the most common toxic symptoms. There was a lower incidence of toxic levels and an absence of toxic symptoms in the later stages of the trial.

Fig. 2 shows the outcome of the trial at two years. According to the original intention to treat, there was a 2-year mortality of 24 per cent in the treatment group compared with 18 per cent in the control group. This difference was not statistically significant.

Further analysis of the mortality data is shown in Table 4. According to the original intention to treat, there were 4 deaths associated with reinfarction in the treatment group, and none in the control

Table 3 Incidence of toxic plasma phenytoin levels and symptoms attributable to phenytoin toxicity

\begin{tabular}{llllllllll}
\hline \multicolumn{7}{c}{ Week after entry } \\
\cline { 2 - 9 } & 4 & 8 & 16 & 24 & 36 & 52 & 78 & 104 \\
\hline $\begin{array}{l}\text { Number of patients } \\
\text { on phenytoin with } \\
\text { plasma levels in } \\
\text { toxic range }\end{array}$ & 8 & 12 & 8 & 10 & 5 & 4 & 5 & 0 \\
$\begin{array}{c}\text { Number of patients } \\
\text { with symptoms } \\
\text { attributable to } \\
\text { phenytoin toxicity }\end{array}$ & 5 & 3 & 3 & 0 & 0 & 0 & 0 & 0 \\
\hline
\end{tabular}




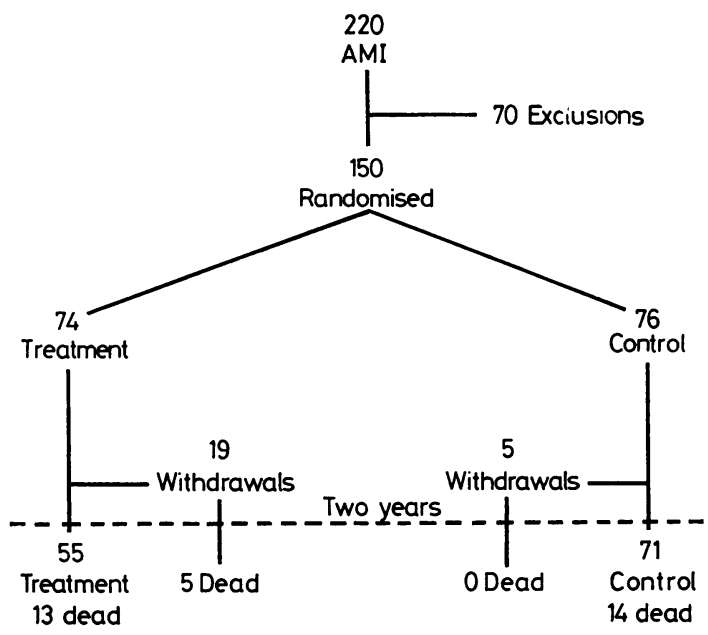

Fig. 2 The outcome of patients entered into the study and followed to two years.

group. This difference was not statistically significant. There were no significant differences between the two groups in the time of death since the onset of a new major symptom. In the highest risk group defined by combined electromechanical complications during their course in CCU, there were 3 instantaneous deaths in the treatment group and 6 instantaneous deaths in the control group. Again, this difference was not statistically significant. Of the 32 deaths in the study, 4 were the result of a non-cardiac cause and in one patient the cause was unknown. The remainder were considered to have died as a result of a cardiac event. In patients receiving phenytoin who died, all except one had a therapeutic plasma level at their last visit to the hospital.

There were 5 non-fatal reinfarctions in the treatment group and an identical number in the control group during the 2-year follow up period.

Table 4 Deaths at two years

\begin{tabular}{lllll}
\hline & $\begin{array}{l}\text { Treatment } \\
\text { group }\end{array}$ & $\begin{array}{l}\text { With- } \\
\text { drawals } \\
\text { from } \\
\text { treatment } \\
\text { group }\end{array}$ & $\begin{array}{l}\text { Control } \\
\text { group }\end{array}$ & $\begin{array}{l}\text { With- } \\
\text { drawals } \\
\text { from } \\
\text { control } \\
\text { group }\end{array}$ \\
\hline $\begin{array}{l}\text { Total deaths } \\
\begin{array}{c}\text { Mode of death } \\
\text { Instantaneous }\end{array}\end{array}$ & 13 & 5 & 14 & 0 \\
$\begin{array}{l}\text { Sudden } \\
\text { More than }\end{array}$ & 3 & 2 & 8 & 0 \\
$\begin{array}{c}\text { 24 hours } \\
\begin{array}{c}\text { Death associated } \\
\text { with confirmed } \\
\text { reinfarction }\end{array}\end{array}$ & 5 & 2 & 4 & 0 \\
\hline
\end{tabular}

\section{Discussion}

Although treatment and control groups were well matched for most factors affecting prognosis, there was an excess of anterior infarcts in the control group and an excess of inferior infarcts in the treatment group. This mismatching would be expected to bias the trial in favour of the treatment group as the multicentre practolol study has shown a lower 2-year mortality in patients with inferior infarctions (Multicentre International Study, 1975). However the multicentre practolol study also shows that treatment was only effective in anterior infarctions. If this is true for phenytoin therapy also, it would offset the trend for a better outcome for the treatment group in our trial.

In the control group more patients were receiving digitalis and there was a higher incidence of clinical heart failure, thus again the trial would tend to favour the treatment group. Despite this bias, longterm treatment with phenytoin failed to show any beneficial effect on 2-year mortality, or any reduction in the incidence of instantaneous or sudden death. Though only a little more than half of the treatment group patients had therapeutic plasma levels of phenytoin at any one time, it is important to note that the last measured plasma levels were therapeutic in the majority of patients who died while on phenytoin treatment.

Patients with both electrical and mechanical complications after infarction have a worse longterm prognosis than patients with only one or neither of these complications (Wilhelmsson et al., 1974). Even in this high risk group, however, there was no reduction in total mortality with phenytoin therapy; there was a reduction in numbers of instantaneous deaths, but the number of patients in the group were too small for this difference to be significant. This group, however, may be a useful one in which to study antiarrhythmic drugs in future trials. Any beneficial effects should be more distinct in this high risk group compared with the full range of patients.

A major aim of this study was to maintain therapeutic phenytoin plasma levels consistently. Despite our vigorous attempts to attain this ideal, at best only three-quarters of the patients had therapeutic phenytoin levels at any visit, and at worst, only half. There is a wide intersubject variation in phenytoin metabolism as shown by the wide variety of biological half-lives previously reported ( 7 to 42 hours) (Arnold and Gerber, 1970). Further, it appears that phenytoin metabolism in an individual exhibits enzyme saturatable characteristics, and disproportionate changes in plasma levels may, therefore, occur with small changes in dose 
when the metabolic enzyme systems become saturated (Perrier et al., 1976). Though efforts were made to obtain a high degree of patient compliance, there was no satisfactory measure to assess our success in this respect other than to determine whether phenytoin had been taken or not. Our difficulties with controlling plasma levels of treatment have significant connotations for future longterm antiarrhythmic trials. Unless an antiarrhythmic drug has predictable and uniform metabolism, a high degree of plasma level control will be difficult to achieve. If the variations are such that frequent changes in dose are required, it will be difficult to conduct a satisfactory double-blind study.

There was a high withdrawal rate in this study from the treatment group, of the order of that seen in the practolol study and some of the earlier anticoagulant studies. Idiosyncratic phenomena, mainly skin rashes, were the usual cause of withdrawal. Phenytoin toxic symptoms usually responded to reduction in dose of the drug. The incidence of serious side effects was so high $(14 \%)$ that use of phenytoin as a prophylactic antiarrhythmic agent is contraindicated in the broad range of patients.

The authors wish to thank Professor R. R. H. Lovell for his helpful advice and guidance. They also wish to acknowledge the invaluable assistance of Marilyn Pring and the financial support of the Dreyfus Medical Foundation in the conduct of the trial.

\section{References}

Ablmark, G., Saetre, H., and Kosgren, M. (1974). Reduction of sudden deaths after myocardial infarction. Lancet, 2, 1563.
Amsterdam, E. A., Wolfson, S., and Gorlin, R. (1968). Effect of therapy on survival in angina pectoris (abstract). Annals of Internal Medicine, 68, 1151.

Arnold, K., and Gerber, N. (1970). The rate of decline of diphenylhydantoin in human plasma. Clinical Pharmacology and Therapeutics, 11, 121-134.

Bigger, J. T., Jr., Schmidt, D. H., and Kutt, H. (1968). Relationship between the plasma level of diphenylhydantoin sodium and its cardiac antiarrhythmic effects. Circulation, 38, 363-374.

Collaborative Group (1971). Phenytoin after recovery from myocardial infarction, controlled trial in 568 patients. Lancet, 2, 1055-1057.

Kosowsky, B. D., Taylor, J., Lown, B., and Ritchie, R. F. (1973). Long term use of procainamide following acute myocardial infarction. Circulation, 47, 1204-1210.

Multicentre International Study (1975). Improvement in prognosis of myocardial infarction by long-term betaadrenoreceptor blockade using practolol. British Medical fournal, 3, 735-740.

Perrier, D., Rapp, R., Young, B., Kosterbauder, H., Cady, W. Pancorbo, S., and Hackman, J. (1976). Maintenance of therapeutic phenytoin plasma levels via intramuscular administration. Annals of Internal Medicine, 85, 318-321.

Reynolds, J. L., and Whitlock, R. M. L. (1972). Effects of a beta-adrenergic receptor blocker in myocardial infarction treated for one year from onset. British Heart fournal, 34, 252-259.

Wallace, J. E. (1968). Determination of diphenylhydantoin in biological specimens by ultraviolet spectrophotometry. Analytical Chemistry, 40, 978-980.

Wilhelmsson, C., Wilhelemsen, L., Vedin, J. A., Tibblin, G. and Werkö, L. (1974). Reduction of sudden deaths after acute myocardial infarction by treatment with alprenolol. Lancet, 2, 1157-1160.

World Health Organization. Regional Office for Europe (1971). Working Group on Ischaemic Heart Disease Registers. W.H.O., Copenhagen.

Requests for reprints to Dr J. Graeme Sloman, Department of Cardiology, Royal Melbourne Hospital, Victoria 3050, Australia. 